\title{
Together We Stand, Divided We Fall: A Multidisciplinary Approach in Complicated Acute Pancreatitis
}

\author{
Jorge Paulino ${ }^{1, *(\mathbb{D})}$, Gonçalo Ramos ${ }^{2}$ and Filipe Veloso Gomes ${ }^{3}$ (1) \\ 1 Department of Surgery, Centro Hepatobiliopancreático e Transplantação, Centro Hospitalar Universitário de \\ Lisboa Central, Hospital Curry Cabral, Universidade Nova de Lisboa, 1050-099 Lisboa, Portugal \\ 2 Department of Gastroenterology, Centro Hospitalar Universitário de Lisboa Central, Hospital dos Capuchos, \\ Universidade Nova de Lisboa, 1169-050 Lisboa, Portugal; goncalo.o.ramos@gmail.com \\ 3 Interventional Radiology Unit, Centro Hepatobiliopancreático e Transplantação, Centro Hospitalar \\ Universitário de Lisboa Central, Hospital Curry Cabral, Universidade Nova de Lisboa, \\ 1050-099 Lisboa, Portugal; fvgomes@gmail.com \\ * Correspondence: fusilis@gmail.com
}

Received: 23 August 2019; Accepted: 29 September 2019; Published: 3 October 2019

\begin{abstract}
Acute pancreatitis (AP) is an inflammatory condition with a mild course in most patients, but $20-30 \%$ evolve to single or multiple organ dysfunction and pancreatic/peripancreatic necrosis, with potentially infected collections. In the first weeks of disease, a systemic inflammatory syndrome (SIRS) dominates the clinical setting, and early management decisions in this precocious phase can change the course of the disease. Imaging is crucial in the diagnosis, and since the adoption of the revised Atlanta classification, four different types of pancreatic/peripancreatic collections have been defined. The management of the complicated forms of AP has been defined by several treatment guidelines, and the main indication for intervention is local infection, preferably in walled-off necrosis. Open surgery necrosectomy is associated with a very high rate of morbimortality, giving a place to different multidisciplinary methodologies, emphasizing drainage and necrosectomy techniques in a "step-up" approach starting from mini-invasive endoscopic drainage and moving, if needed, to progressively more invasive techniques, including interventional radiology and mini-invasive surgery. With the advent of several new technologies in the specialties involved, the complicated AP cases which need drainage and necrosectomy benefit from a new era of multidisciplinary cooperation, permitting higher efficacy with lower levels of morbimortality and reducing hospital stay and costs.
\end{abstract}

Keywords: acute pancreatitis; infection; haemorrhage; necrosectomy; drainage

\section{Introduction}

Acute pancreatitis (AP) is a term meaning an acute inflammatory course of the pancreas with a complete pathogenesis yet to be completed elucidated. Its definition, regardless of the aetiology, is based on the fulfilment of "two out of three" of the following criteria: Clinical (upper abdominal pain), laboratory (serum amylase or lipase $>3$ upper limit of normal) and imaging (computed tomography, magnetic resonance, ultrasonography) [1].

In a great majority of cases, AP is a self-limiting illness with appropriately supportive treatment. In fact, most patients with AP recover within a week, whereas patients with severe forms have a high risk of multi-organ failure [2]. These extreme forms of AP develop in $20 \%$ of patients, with a historical mortality risk of as high as $30 \%$ [3].

There have been many clinical scoring systems proposed to predict severity in the early phase of AP (Ranson [4], Modified Glasgow [5], Systemic Inflammatory Response Syndrome (SIRS) [6], and Acute 
Physiology, Age, Chronic Health Evaluation II (APACHE II) [7]), together with imaging-guided severity indexes (Balthazar [8], computed tomography severity index [9]), or even single laboratory parameters such as C-reactive protein, procalcitonin or blood urea nitrogen. Two recent systematic reviews confirmed the APACHE II and simple bedside index as the most accurate severity prediction scores $[10,11]$. In clinical practice, however, these scoring systems are irrelevant because of their complexity and low feasibility, and the decisions are based on real-time measurements [12].

During the first weeks of AP, there is a release of inflammatory mediators, initiating a systemic inflammatory response syndrome (SIRS) that may induce single or multiorgan failure with or without concomitant necrosis, infection, and possibly death [6]. This response can be similar, or even identical, to a clinical one arising from infection, and it was described for the first time as an inflammatory process, independent of its cause [13]. Its manifestations include, but are not limited to, more than one of the following: Temperature $>38^{\circ} \mathrm{C}$ or $<36^{\circ} \mathrm{C}$; tachycardia $>90 \mathrm{bpm}$; tachypnea $>20 /$ min or $\mathrm{pCO}_{2}<$ $32 \mathrm{mmHg}$; and white blood cell count $>12000 / \mathrm{cu} \mathrm{mm}$ (cubic millimeter) or $<4000 / \mathrm{cu} \mathrm{mm}$; or $>10 \%$ immature (band) forms [14].

Imaging is certainly very useful for the diagnosis of AP, but it is not an absolute requirement for it, as in cases of prolonged period between clinical complaints and presentation, patients with low level of consciousness, or clinical situations with a difficult differential diagnosis with other acute abdomen scenarios.

Since the adoption of the revised Atlanta classification in 2012, AP has been defined in three grades of severity: Mild, moderately severe and severe. Of these three grades, it is the severe form of $\mathrm{AP}$ that presents persistent organ failure for more than 48 hours despite the presence or the absence of local complications [6].

The local complications of AP have been classified in four types of collections based on radiologic and pathologic features, independently of the clinical prediction of gravity. Any of these types of fluid collections may be sterile or infected. This determinant-based classification defines two types of collections in the setting of interstitial edematous pancreatitis (acute peripancreatic fluid collections and pancreatic pseudocysts) and two other types of collections in necrotizing pancreatitis (acute necrotic collections before demarcation and walled-off necrosis (WON) [15]. This last type of collections characteristically has encapsulating walls that are developed four or more weeks after the onset of AP according the revised Atlanta classification. Nevertheless, a multicenter study demonstrated that $43 \%$ of demarcated collections already developed within the first three weeks after onset of necrotizing pancreatitis [16].

\section{Management of Complicated Acute Pancreatitis}

Since it is one of the most common gastrointestinal disorders that requires hospitalization, AP annually leads to huge inpatient costs, requiring evidence-based treatment guidelines provided by the pancreatic community: The International Association of Pancreatology (IAP) and the American Pancreatic Association (APA) [3,17]. Indeed, a systematic review of guidelines for AP emphasized the need for a high-quality update to influence several important aspects of the medical and surgical management of AP [18].

There are two overlapping phases of AP (early and late), the first one being considered in the first two weeks of the disease onset. Crucial early management decisions can change the course of $\mathrm{AP}$, validating recent guidelines addressing the first $48-72$ hours of admission [19]. These guidelines aim at providing evidence-based recommendations for the treatment of AP and consider both the revised Atlanta classification [6] and the most recent consensus conference on interventions for necrotizing pancreatitis [20].

One of the most cited guidelines in literature was released in 2013 by the IAP/APA working group [1], and it incorporated 12 main topics, 38 clinical questions, and their answers.

Recently, other evidence-based international consensus statements on the management of severe AP have appeared, such as the World Society of Emergency Surgery guidelines, published in 2019. 
Some of these statements obtained a strong level of evidence, namely most aspects of the management in the Intensive Care Unit (ICU), opposite to others showing a quite weak evidence, such as surgical strategies that still require further studies [21].

The indications to intervene in necrotizing pancreatitis are local infections, preferably WON. Even without a documented infection, clinical deterioration for several weeks after onset justifies intervention. Almost $50 \%$ of patients operated due to persisting organ failure without signs of infected necrosis have an unexpectedly positive bacterial culture in the operative specimen [22]. In sterile necrotizing pancreatitis, other less frequent indications are clinical situations such as abdominal compartment syndrome, acute bleeding, bowel ischemia, or any type of obstruction due to mass effect [22]. Another late complication of necrotizing pancreatitis, the "disconnected duct syndrome," may be found in up to $40 \%$ of these patients, half of them requiring an intervention due to symptoms related to a sustained main pancreatic duct injury [23].

The surgical "step-down" approach: Classically, the standard of care for infected pancreatic necrosis was, until recently, surgical debridement unless patients were too ill to undergo surgical intervention [6]. Accordingly, this "step down" approach adopted open necrosectomy to play a primary therapeutic role, with less invasive methods used for residual or subsequent collections (Figure 1). This concept began to be challenged by anecdotal reports of better outcomes with less aggressive approaches, recognizing that open necrosectomy often makes patients sicker, and outcomes may be improved by simply delaying it [24]. Moreover, the understanding that most patients with sterile pancreatic necrosis and some with infected necrosis could be successfully managed without necrosectomy has influenced the change of the paradigm [25].

Nowadays, it is accepted that postponing surgical interventions for more than four weeks after the onset of AP results in lower mortality rates. A recent systematic review and meta-analysis compared timing of operative interventions in three different cut-offs ( $72 \mathrm{~h}, 12$ days and 30 days) and concluded that late surgery had a clear survival benefit in all of them [26].
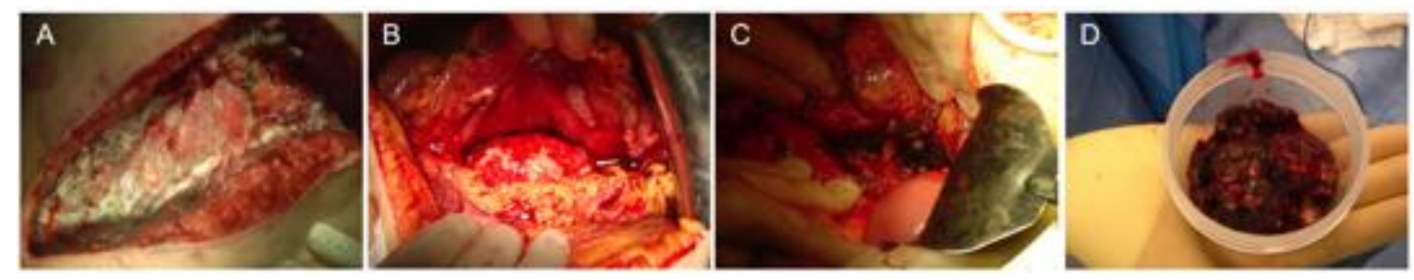

Figure 1. Open necrosectomy (sequential steps). (A) Transverse laparotomy, (B) retrogastric approach, (C) major artery skeletonized, and (D) necrosectomy specimen.

The multidisciplinary "step-up" approach: As an alternative to open necrosectomy, less invasive techniques have progressively demonstrated better results, namely percutaneous drainage [27], endoscopic transgastric drainage [28] and retroperitoneal, minimally invasive necrosectomy [29]. These techniques might be used in the so-called "step up" approach, aiming at controlling the source of the infection instead of trying to completely remove the infected necrotic tissue, relying on less invasive approaches in the first step of treatment and progressively climbing up to an open necrosectomy as a last option [30]. A flowchart reporting the pathways of management of acute pancreatitis is depicted in Figure 2.

The primary step is the drainage of the infected fluid (endoscopically or percutaneously), which may defer or even avoid surgical necrosectomy. If there is no clinical improvement, the next step is a video-assisted retroperitoneal debridement [31].

A multicenter randomized trial from the Dutch Pancreatitis Study Group (the PANTER-Patients with Acute Necrotizing Pancreatitis-trial) demonstrated how the "step-up" approach decreased mortality, major complications and costs, when compared to primary necrosectomy among patients with necrotizing pancreatitis and infected necrotic tissue [32]. 
In the PANTER study, 35\% of patients were successfully treated with percutaneous drainage alone, without subsequent debridement. More than $95 \%$ of patients with infected necrosis can be drained percutaneously, but a promising alternative is undoubtedly the NOTES (natural orifice transluminal endoscopic surgery) route for drainage and/or necrosectomy. The endoscopic technique of cystogastrostomy has evolved in the last decade to eventually become the first choice as minimally invasive necrosectomy in most cases, when compared to minimally invasive intervention; two pilot trials, the Pancreatitis Endoscopic Transgastric versus Primary Necrosectomy in Patients with Infected Pancreatic Necrosis (PENGUIN) [33] and the Transluminal Endoscopic Step-Up approach versus Minimally Invasive Surgical Step-Up approach (TENSION) [34] showed at least an equivalence between the two procedures.

\section{VPR}

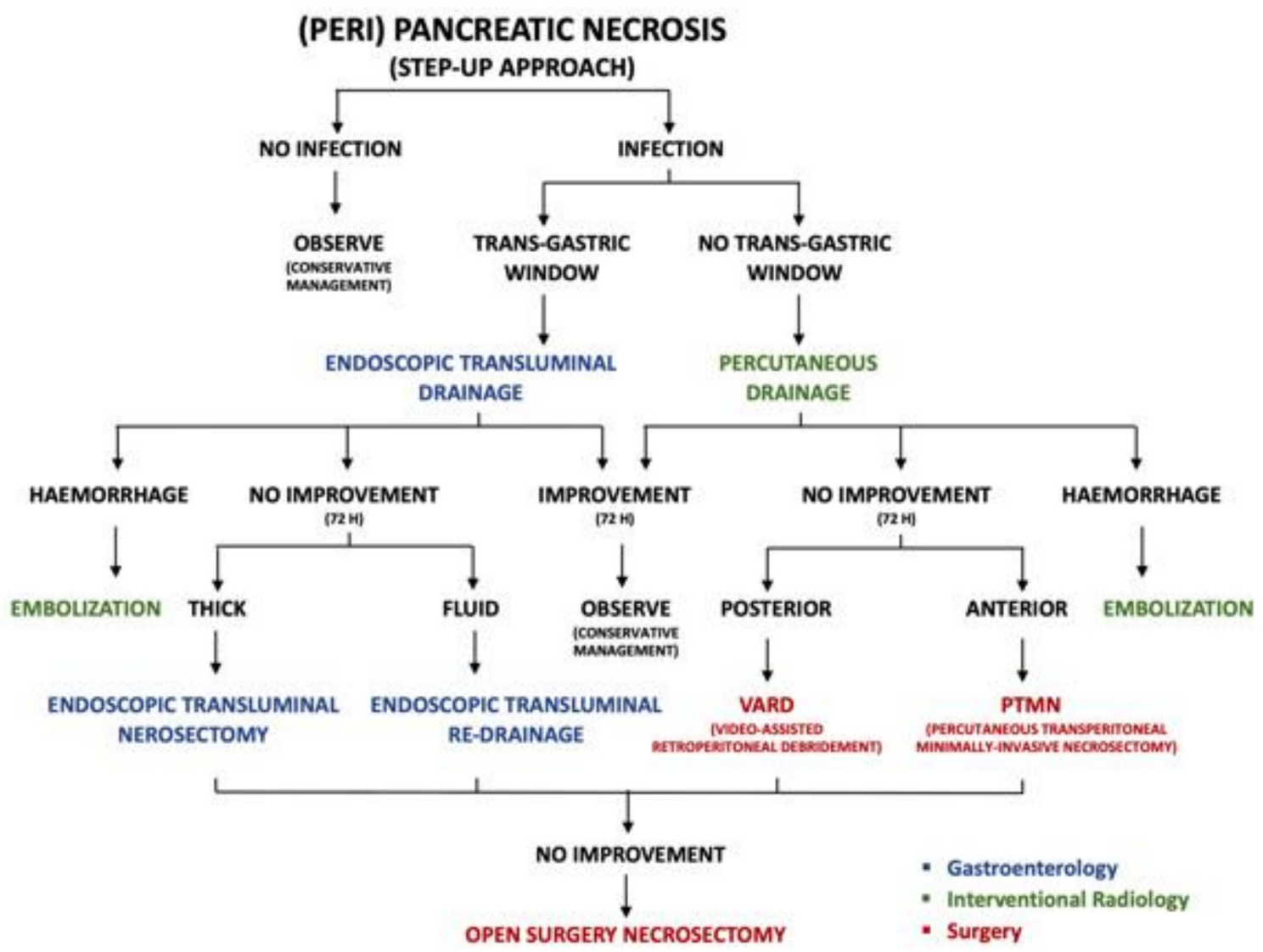

Figure 2. Pathways of management of complicated acute pancreatitis. Types of interventions are differentiated by colors: Surgery in red, gastroenterology in blue, interventional radiology in green.

Transgastric EUS (endo-ultrasonography) guided drainage is the treatment of choice for late and persistent pancreatic collections, except, according with some authors, some lateral and retrocolic-ones [35]. However, in the case of failure of endoscopic or catheter drainage, the methodology for necrosectomy is unclear.

To achieve a minimally invasive necrosectomy, several approaches have been described that utilize endoscopic approaches, image-guided techniques and small incision open surgeries and are performed by gastroenterologists, interventional radiologists or surgeons. This has resulted in a confusing array of terms describing these procedures, demanding a common terminology. A classification of invasive procedures has proposed that describes visualization, route and purpose (the VRP Classification) [36], establishing different competences for each involved specialty: i) Per-os transpapillary route (gastroenterology); ii) per-os transmural route (gastroenterology) (Figure 3); iii) percutaneous 
retroperitoneal route (surgeon/interventional radiologist); iv) percutaneous transperitoneal route (surgeon) (Figure 4); and percutaneous transmural route (surgeon/interventional radiologist).
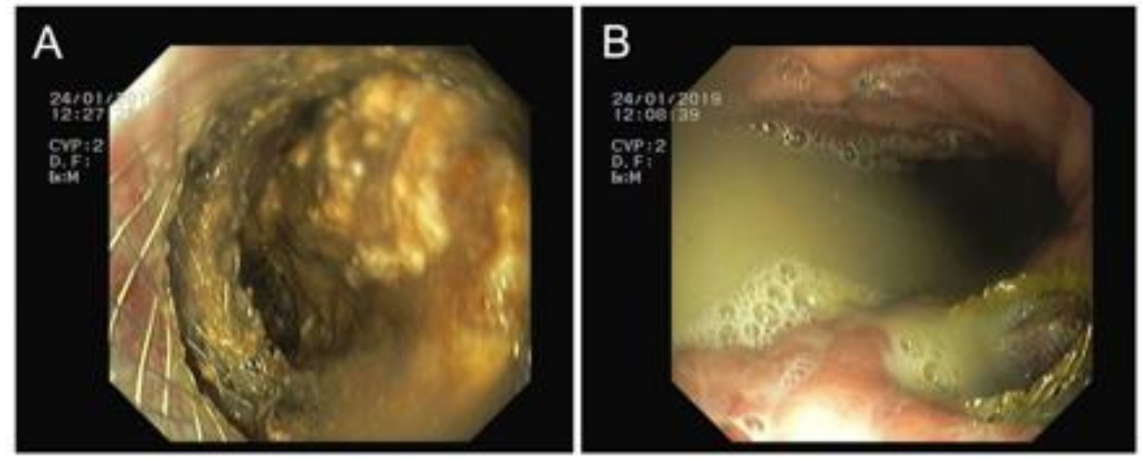

Figure 3. Transmural route. (A) Necrosectomy through the prosthesis and (B) purulent drainage to the gastric lumen.
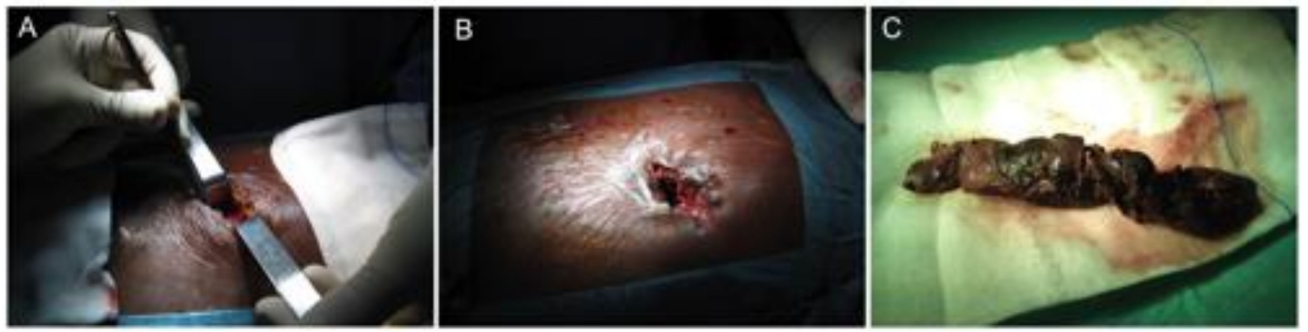

Figure 4. Transperitoneal route. (A) Minimally invasive skin incision, (B) lesser sac entrance, and (C) complete necrosectomy specimen.

More recently (2018), The European Society of Gastrointestinal Endoscopy (ESGE) released several evidence-based multidisciplinary guidelines [37], such as: (i) The fine needle aspiration of (peri)pancreatic collections only if infection is suspected; (ii) EUS-guided access should be preferred to conventional transmural drainage in a first approach; and (iii) simultaneous drainage (endoscopic, transmural, and percutaneous) in WON extending to pelvic paracolic gutters.

Any variety of minimally invasive necrosectomy is dependent of the proper control of hemorrhage to be successful. Moreover, pancreatitis itself can cause both thrombotic and hemorrhagic complications through the formation of a fluid collection, with a significant morbidity and mortality. These complications occur in between $1 \%$ and $23 \%$ of pancreatitis cases, with venous being significantly more common than arterial ones [38].

Despite their rarity, it is important to identify and treat arterial complications as early as possible, as they are associated with a mortality of $34-52 \%$ [39]. Arterial wall disruption can occur due to the exposure to the free lipolytic and proteolytic enzymes, leading to pseudo-aneurysm formation or spontaneous arterial rupture.

Bleeding can also occur from the disruption of the wall of a pseudocyst or WON. The presence of endoscopically or surgically inserted drains can also directly traumatize vessels. They can perpetuate local inflammation and diminish arterial wall integrity.

Any form of necrosectomy can disrupt arterial viability and cause multi-organ failure, necrosis, anticoagulation and underlying vasculitis [40].

Symptomatic pseudo-aneurysms present abdominal pain as the main complaint in $29.5 \%$ of patients, followed by bleeding into the gastrointestinal tract in $26.5 \%$. They can occur in the splenic artery $(35-50 \%)$, gastroduodenal artery (30\%, Figure 5), or pancreaticoduodenal arcades (20-25\%) [41]. Imaging diagnosis is based in the Angio-Computed Tomography (CT) and ultra-sonography Doppler imaging (Figure 5). Treatment is performed by trans-arterial embolization through the placement of 
coils or other embolic agents in the proximal and distal feeding vessel (the "frontdoor" and "backdoor" technique) to isolate inflow and prevent collateral back filling (Figure 5).
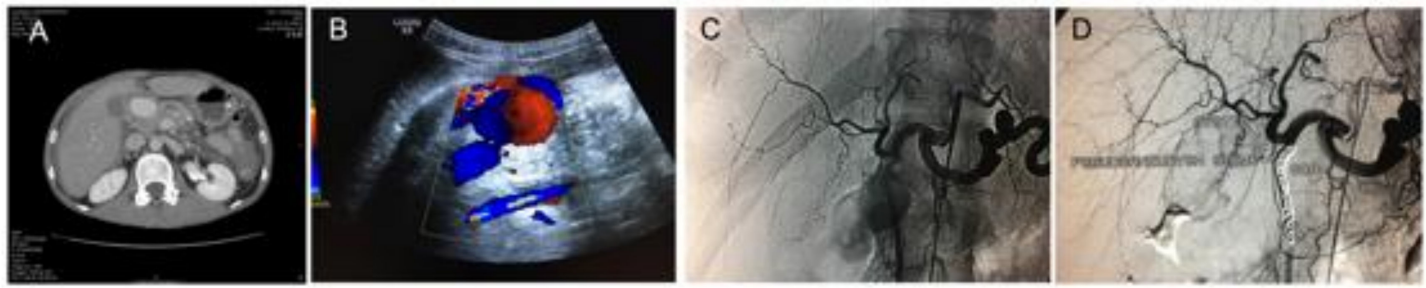

Figure 5. Diagnosis and treatment of a pseudo-aneurysm of the gastroduodenal artery in a patient with severe acute pancreatitis. (A) Abdominal angio-CT revealing a large contrast-enhanced mass, (B) characteristic swirl flow in abdominal ultrasound-Yin-Yang sign, (C) digital subtraction angiography (DSA) showing the large pseudoaneurysm projected over the gastroduodenal artery, and (D) DSA showing the post trans-arterial embolization of the gastroduodenal artery with multiple coils.

Interventional radiology also has a very important rescuing contribution to the approach of complicated cases, both in the imaging diagnosis and treatment of hemorrhagic situations after necrosectomy procedures by endoscopic or previous surgery [42].

With the rise of minimally invasive techniques (angiographic, percutaneous, or endoscopic), the role of surgery has become restricted. Still, despite constant technological advances in other areas of intervention, open surgery continues to play a rescue role in hemorrhage control where other methods are not available or technically achievable. In Figure 6, we present the case of a patient transferred to our center with an "open abdomen" with tamponade to control an overwhelming hemorrhage caused by acute pancreatitis. He had been submitted to more than one open necrosectomy before being transferred to our center. The first approach was by intervention radiology with the trans-arterial embolization of the splenic artery, followed by open surgery with abdominal closure.
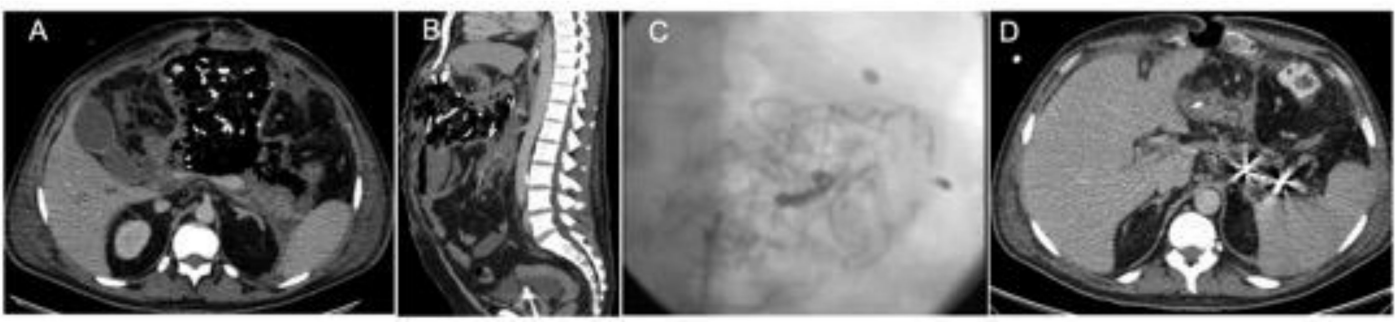

Figure 6. Splenic artery trans-arterial embolization by the placement of coils in a patient with acute pancreatitis patient submitted to an "open abdomen" tamponade for hemorrhage control. (A) Axial CT view, (B) sagittal CT view, (C) angiographic view post-embolization, and (D) axial CT control after embolization, with metal artifacts from the coils placed in the splenic artery.

Conventional surgery still has a role in the treatment of complicate AP when percutaneous or endoscopic strategies fail to improve the patient, namely: (i) Abdominal compartment syndrome, requiring surgical decompression, if other conservative measures are insufficient $[43,44]$; (ii) cholecystectomy: Only in cases where a deferred strategy that enables the resolution of fluid collections is not possible [45]; and (iii) mechanical bowel obstruction [46].

\section{Conclusions}

Complicated acute pancreatitis remains a devastating disease that is associated with mortality up to $30 \%$ and enormous and rising inpatient costs [17]. Early triage and referral to high-volume centers with defined protocols and multidisciplinary approaches are ways to drop of the global mortality described in literature in the last few decades. 
Interventions for necrotizing pancreatitis have evolved considerably over recent years, with a minimally invasive step-up approach now preferred. The best methodology, according to the literature, is endoscopic and/or percutaneous catheter drainage followed, if needed, by endoscopic or minimally invasive surgical necrosectomy.

A highly differentiated team with a special interest in necrotizing pancreatitis is mandatory to succeed with the best outcomes, clinically and financially. Such a team must integrate dedicated pancreatic surgeons, gastroenterologists, and intervention radiologists beyond intensivists in appropriate intensive care unit facilities.

Author Contributions: All authors discussed this review, selected the presented cases and performed the clinical work and the final manuscript.

Funding: This research received no external funding.

Acknowledgments: The authors thank F.O. Martins for kindly providing three high quality pictures.

Conflicts of Interest: The authors declare no conflict of interest.

\section{References}

1. Working Group IAP/APA Acute Pancreatitis Guidelines. IAP/APA evidence-based guidelines for the management of acute pancreatitis. Pancreatology 2013, 13, e1-e15. [CrossRef] [PubMed]

2. Van Dijk, S.M.; Hallensleben, N.D.L.; van Santvoort, H.C.; Fockens, P.; van Goor, H.; Bruno, M.J.; Besselink, M.G.; Dutch Pancreatitis Study Group. Acute pancreatitis: Recent advances through randomised trials. Gut 2017, 66, 2024-2032. [CrossRef] [PubMed]

3. Yadav, D.; Lowenfels, A.B. The epidemiology of pancreatitis and pancreatic cancer. Gastroenterology 2013, 144, 1252-1261. [CrossRef] [PubMed]

4. Ranson, J.H.; Rifkind, K.M.; Turner, J.W. Prognostic signs and nonoperative peritoneal lavage in acute pancreatitis. Surg. Gynecol. Obstet. 1976, 143, 209-219. [PubMed]

5. Blamey, S.L.; Imrie, C.W.; O'Neill, J.; Gilmour, W.H.; Carter, D.C. Prognostic factors in acute pancreatitis. Gut 1984, 25, 1340-1346. [CrossRef] [PubMed]

6. Banks, P.A.; Freeman, M.L. Practice Parameters Committee of the American College of, Gastroenterology. Practice guidelines in acute pancreatitis. Am. J. Gastroenterol. 2006, 101, 2379-2400. [CrossRef]

7. Knaus, W.A.; Draper, E.A.; Wagner, D.P.; Zimmerman, J.E. APACHE II: A severity of disease classification system. Crit. Care Med. 1985, 13, 818-829. [CrossRef]

8. Balthazar, E.J.; Robinson, D.L.; Megibow, A.J.; Ranson, J.H. Acute pancreatitis: Value of CT in establishing prognosis. Radiology 1990, 174, 331-336. [CrossRef]

9. Simchuk, E.J.; Traverso, L.W.; Nukui, Y.; Kozarek, R.A. Computed tomography severity index is a predictor of outcomes for severe pancreatitis. Am. J. Surg. 2000, 179, 352-355. [CrossRef]

10. Harshit Kumar, A.; Singh Griwan, M. A comparison of APACHE II, BISAP, Ranson's score and modified CTSI in predicting the severity of acute pancreatitis based on the 2012 revised Atlanta Classification. Gastroenterol. Rep. 2018, 6, 127-131. [CrossRef]

11. Valverde-Lopez, F.; Matas-Cobos, A.M.; Alegria-Motte, C.; Jimenez-Rosales, R.; Ubeda-Munoz, M.; Redondo-Cerezo, E. BISAP, RANSON, lactate and others biomarkers in prediction of severe acute pancreatitis in a European cohort. J. Gastroenterol. Hepatol. 2017, 32, 1649-1656. [CrossRef]

12. Trikudanathan, G.; Wolbrink, D.R.J.; van Santvoort, H.C.; Mallery, S.; Freeman, M.; Besselink, M.G. Current Concepts in Severe Acute and Necrotizing Pancreatitis: An Evidence-Based Approach. Gastroenterology 2019, 156, 1994-2007. [CrossRef] [PubMed]

13. Bone, R.C.; Balk, R.A.; Cerra, F.B.; Dellinger, R.P.; Fein, A.M.; Knaus, W.A.; Schein, R.M.; Sibbald, W.J. Definitions for sepsis and organ failure and guidelines for the use of innovative therapies in sepsis. The ACCP/SCCM Consensus Conference Committee. American College of Chest Physicians/Society of Critical Care Medicine. Chest 1992, 101, 1644-1655. [CrossRef] [PubMed]

14. Klein Klouwenberg, P.M.; Ong, D.S.; Bonten, M.J.; Cremer, O.L. Classification of sepsis, severe sepsis and septic shock: The impact of minor variations in data capture and definition of SIRS criteria. Intensive Care Med. 2012, 38, 811-819. [CrossRef] [PubMed] 
15. Dellinger, E.P.; Forsmark, C.E.; Layer, P.; Levy, P.; Maravi-Poma, E.; Petrov, M.S.; Shimosegawa, T.; Siriwardena, A.K.; Uomo, G.; Whitcomb, D.C.; et al. Determinant-based classification of acute pancreatitis severity: An international multidisciplinary consultation. Ann. Surg. 2012, 256, 875-880. [CrossRef]

16. Van Grinsven, J.; van Brunschot, S.; van Baal, M.C.; Besselink, M.G.; Fockens, P.; van Goor, H.; van Santvoort, H.C.; Bollen, T.L. Dutch Pancreatitis Study Group. Natural History of Gas Configurations and Encapsulation in Necrotic Collections During Necrotizing Pancreatitis. J. Gastrointest. Surg. 2018, 22, 1557-1564. [CrossRef] [PubMed]

17. Peery, A.F.; Dellon, E.S.; Lund, J.; Crockett, S.D.; McGowan, C.E.; Bulsiewicz, W.J.; Gangarosa, L.M.; Thiny, M.T.; Stizenberg, K.; Morgan, D.R.; et al. Burden of gastrointestinal disease in the United States: 2012 update. Gastroenterology 2012, 143, 1179-1187. [CrossRef]

18. Loveday, B.P.; Srinivasa, S.; Vather, R.; Mittal, A.; Petrov, M.S.; Phillips, A.R.; Windsor, J.A. High quantity and variable quality of guidelines for acute pancreatitis: A systematic review. Am. J. Gastroenterol. 2010, 105, 1466-1476. [CrossRef]

19. Crockett, S.D.; Wani, S.; Gardner, T.B.; Falck-Ytter, Y.; Barkun, A.N.; American Gastroenterological Association Institute Clinical Guidelines Committee. American Gastroenterological Association Institute Guideline on Initial Management of Acute Pancreatitis. Gastroenterology 2018, 154, 1096-1101. [CrossRef]

20. Freeman, M.L.; Werner, J.; van Santvoort, H.C.; Baron, T.H.; Besselink, M.G.; Windsor, J.A.; Horvath, K.D.; van Sonnenberg, E.; Bollen, T.L.; Vege, S.S.; et al. Interventions for necrotizing pancreatitis: Summary of a multidisciplinary consensus conference. Pancreas 2012, 41, 1176-1194. [CrossRef]

21. Leppaniemi, A.; Tolonen, M.; Tarasconi, A.; Segovia-Lohse, H.; Gamberini, E.; Kirkpatrick, A.W.; Ball, C.G.; Parry, N.; Sartelli, M.; Wolbrink, D.; et al. 2019 WSES guidelines for the management of severe acute pancreatitis. World J. Emerg. Surg. 2019, 14, 27. [CrossRef] [PubMed]

22. Rodriguez, J.R.; Razo, A.O.; Targarona, J.; Thayer, S.P.; Rattner, D.W.; Warshaw, A.L.; Fernandez-del Castillo, C. Debridement and closed packing for sterile or infected necrotizing pancreatitis: Insights into indications and outcomes in 167 patients. Ann. Surg. 2008, 247, 294-299. [CrossRef] [PubMed]

23. Beck, W.C.; Bhutani, M.S.; Raju, G.S.; Nealon, W.H. Surgical management of late sequelae in survivors of an episode of acute necrotizing pancreatitis. J. Am. Coll. Surg. 2012, 214, 682-688. [CrossRef] [PubMed]

24. Hartwig, W.; Maksan, S.M.; Foitzik, T.; Schmidt, J.; Herfarth, C.; Klar, E. Reduction in mortality with delayed surgical therapy of severe pancreatitis. J. Gastrointest. Surg. 2002, 6, 481-487. [CrossRef]

25. Adler, D.G.; Chari, S.T.; Dahl, T.J.; Farnell, M.B.; Pearson, R.K. Conservative management of infected necrosis complicating severe acute pancreatitis. Am. J. Gastroenterol. 2003, 98, 98-103. [CrossRef] [PubMed]

26. Mowery, N.T.; Bruns, B.R.; MacNew, H.G.; Agarwal, S.; Enniss, T.M.; Khan, M.; Guo, W.A.; Cannon, J.W.; Lissauer, M.E.; Duane, T.M.; et al. Surgical management of pancreatic necrosis: A practice management guideline from the Eastern Association for the Surgery of Trauma. J. Trauma Acute Care Surg. 2017, 83, 316-327. [CrossRef]

27. Freeny, P.C.; Hauptmann, E.; Althaus, S.J.; Traverso, L.W.; Sinanan, M. Percutaneous CT-guided catheter drainage of infected acute necrotizing pancreatitis: Techniques and results. AJR Am. J. Roentgenol. 1998, 170, 969-975. [CrossRef]

28. Papachristou, G.I.; Takahashi, N.; Chahal, P.; Sarr, M.G.; Baron, T.H. Peroral endoscopic drainage/debridement of walled-off pancreatic necrosis. Ann. Surg. 2007, 245, 943-951. [CrossRef]

29. Carter, C.R.; McKay, C.J.; Imrie, C.W. Percutaneous necrosectomy and sinus tract endoscopy in the management of infected pancreatic necrosis: An initial experience. Ann. Surg. 2000, 232, 175-180. [CrossRef]

30. Windsor, J.A. Minimally invasive pancreatic necrosectomy. Br. J. Surg. 2007, 94, 132-133. [CrossRef]

31. Horvath, K.D.; Kao, L.S.; Wherry, K.L.; Pellegrini, C.A.; Sinanan, M.N. A technique for laparoscopic-assisted percutaneous drainage of infected pancreatic necrosis and pancreatic abscess. Surg. Endosc. 2001, 15, 1221-1225. [CrossRef] [PubMed]

32. Van Santvoort, H.C.; Besselink, M.G.; Bakker, O.J.; Hofker, H.S.; Boermeester, M.A.; Dejong, C.H.; van Goor, H.; Schaapherder, A.F.; van Eijck, C.H.; Bollen, T.L.; et al. A step-up approach or open necrosectomy for necrotizing pancreatitis. N. Engl. J. Med. 2010, 362, 1491-1502. [CrossRef] [PubMed]

33. Bakker, O.J.; van Santvoort, H.C.; van Brunschot, S.; Geskus, R.B.; Besselink, M.G.; Bollen, T.L.; van Eijck, C.H.; Fockens, P.; Hazebroek, E.J.; Nijmeijer, R.M.; et al. Endoscopic transgastric vs surgical necrosectomy for infected necrotizing pancreatitis: A randomized trial. JAMA 2012, 307, 1053-1061. [CrossRef] [PubMed] 
34. Van Brunschot, S.; van Grinsven, J.; Voermans, R.P.; Bakker, O.J.; Besselink, M.G.; Boermeester, M.A.; Bollen, T.L.; Bosscha, K.; Bouwense, S.A.; Bruno, M.J.; et al. Transluminal endoscopic step-up approach versus minimally invasive surgical step-up approach in patients with infected necrotising pancreatitis (TENSION trial): Design and rationale of a randomised controlled multicenter trial [ISRCTN09186711]. BMC Gastroenterol. 2013, 13, 161. [CrossRef]

35. Sorrentino, L.; Chiara, O.; Mutignani, M.; Sammartano, F.; Brioschi, P.; Cimbanassi, S. Combined totally mini-invasive approach in necrotizing pancreatitis: A case report and systematic literature review. World J. Emerg. Surg. 2017, 12, 16. [CrossRef] [PubMed]

36. Loveday, B.P.; Petrov, M.S.; Connor, S.; Rossaak, J.I.; Mittal, A.; Phillips, A.R.; Windsor, J.A.; Pancreas Network of New Zealand. A comprehensive classification of invasive procedures for treating the local complications of acute pancreatitis based on visualization, route, and purpose. Pancreatology 2011, 11, 406-413. [CrossRef]

37. Arvanitakis, M.; Dumonceau, J.M.; Albert, J.; Badaoui, A.; Bali, M.A.; Barthet, M.; Besselink, M.; Deviere, J.; Oliveira Ferreira, A.; Gyokeres, T.; et al. Endoscopic management of acute necrotizing pancreatitis: European Society of Gastrointestinal Endoscopy (ESGE) evidence-based multidisciplinary guidelines. Endoscopy 2018, 50, 524-546. [CrossRef]

38. Evans, R.P.; Mourad, M.M.; Pall, G.; Fisher, S.G.; Bramhall, S.R. Pancreatitis: Preventing catastrophic haemorrhage. World J. Gastroenterol. 2017, 23, 5460-5468. [CrossRef]

39. Flati, G.; Andren-Sandberg, A.; La Pinta, M.; Porowska, B.; Carboni, M. Potentially fatal bleeding in acute pancreatitis: Pathophysiology, prevention, and treatment. Pancreas 2003, 26, 8-14. [CrossRef]

40. Sharma, P.K.; Madan, K.; Garg, P.K. Hemorrhage in acute pancreatitis: Should gastrointestinal bleeding be considered an organ failure? Pancreas 2008, 36, 141-145. [CrossRef]

41. Bergert, H.; Hinterseher, I.; Kersting, S.; Leonhardt, J.; Bloomenthal, A.; Saeger, H.D. Management and outcome of hemorrhage due to arterial pseudoaneurysms in pancreatitis. Surgery 2005, 137, 323-328. [CrossRef] [PubMed]

42. Andersson, E.; Ansari, D.; Andersson, R. Major haemorrhagic complications of acute pancreatitis. Br. J. Surg. 2010, 97, 1379-1384. [CrossRef] [PubMed]

43. Kirkpatrick, A.W.; Roberts, D.J.; De Waele, J.; Jaeschke, R.; Malbrain, M.L.; De Keulenaer, B.; Duchesne, J.; Bjorck, M.; Leppaniemi, A.; Ejike, J.C.; et al. Intra-abdominal hypertension and the abdominal compartment syndrome: Updated consensus definitions and clinical practice guidelines from the World Society of the Abdominal Compartment Syndrome. Intensive Care Med. 2013, 39, 1190-1206. [CrossRef] [PubMed]

44. Mentula, P.; Hienonen, P.; Kemppainen, E.; Puolakkainen, P.; Leppaniemi, A. Surgical decompression for abdominal compartment syndrome in severe acute pancreatitis. Arch. Surg. 2010, 145, 764-769. [CrossRef]

45. Nealon, W.H.; Bawduniak, J.; Walser, E.M. Appropriate timing of cholecystectomy in patients who present with moderate to severe gallstone-associated acute pancreatitis with peripancreatic fluid collections. Ann. Surg. 2004, 239, 741-749. [CrossRef] [PubMed]

46. Sunkara, T.; Etienne, D.; Caughey, M.E.; Gaduputi, V. Small Bowel Obstruction Secondary to Acute Pancreatitis. Gastroenterol. Res. 2017, 10, 42-44. [CrossRef]

(C) 2019 by the authors. Licensee MDPI, Basel, Switzerland. This article is an open access article distributed under the terms and conditions of the Creative Commons Attribution (CC BY) license (http://creativecommons.org/licenses/by/4.0/). 